Erratum: "Cigarette smoking and bladder cancer: a new twist in an old saga" by Anthony J. Alberg [J Natl Cancer Inst 2009; 101(22): 1525-1526]. Through no fault of the author, multiple errors appeared in this editorial, which was published in the November 18,2009 issue. The following text is correct. The publisher regrets these errors.

DOI: 10.1093/jnci/djp474

Published by Oxford University Press 2009.

\title{
Cigarette Smoking and Bladder Cancer: A New Twist in an Old Saga?
}

Anthony J. Alberg, James R. Hébert

Cigarette smoking was first evaluated as a risk factor for bladder cancer more than 50 years ago (1). As early as 1964, the Surgeon General's report summarized results from four case-control studies and seven prospective cohort studies. In the case-control studies, the odds ratios in men ranged from 2.0 to 3.3 (2). In the cohort studies, the mean relative risk of bladder cancer mortality in smokers, relative to nonsmokers, was 1.9 (2). The data suggested that the association of smoking with bladder cancer increased according to smoking frequency and depth of inhalation. This evidence led to the conclusion that " . . . available data suggest an association between cigarette smoking and urinary bladder cancer in the male but are not sufficient to support a judgment on the causal significance of the association" (2).

Fifteen years later, the evidence on this topic for the 1979 Surgeon General's report included 17 case-control and eight prospective cohort studies. Compared with nonsmokers, cigarette smokers were consistently shown to have two or more times the risk of developing or dying from bladder cancer, both among men and women. The dose-response relationships were now more completely characterized, and indicated that risk increased with more substantial smoking histories. Compared with persistent smokers, those who had quit smoking had lower bladder cancer risk. Cigarette smoke was now known to contain bladder carcinogens. Based upon this new evidence, the conclusion was " . . . Epidemiological studies demonstrate a significant association between cigarette smoking and cancer of the urinary bladder in both men and women" (3). A few years later, the conclusion of the 1982 Surgeon General's report evolved to “. . . Cigarette smoking is a contributory factor in the development of bladder cancer . . . . The term 'contributory factor' by no means excludes the possibility of a causal role for smoking ...." (4).

As more data accumulated, including careful characterization of the reduced risk in smokers who quit compared with persistent smokers, the evidence was strong enough to conclude in the 1990 Surgeon General's report: "Smoking is a cause of bladder cancer ... " (5). The most recent Surgeon General's report to evaluate this topic, in 2004, cites 30 case-control and 10 cohort studies that bolster the causal association between cigarette smoking and bladder cancer (6).
In this issue, Baris et al. (7) report the results of a case-control study of smoking and bladder cancer. Given the backdrop of the substantial and consistent body of evidence that has accrued since the 1950 s, the most noteworthy finding was that the association between smoking and bladder cancer increased substantially from 1994 to 2004. Odds ratios increased from 2.9 to 4.2 to 5.5 for current smokers, relative to never smokers during each of three successive time intervals, 1994-1998, 1998-2001, and 2001-2004. The authors hypothesize that this trend could be attributable to cigarettes becoming more carcinogenic over time. Despite the trend toward lower "tar" and nicotine concentrations in cigarettes as measured by the Federal Trade Commission's testing protocol, the concentrations of specific carcinogens in cigarette smoke have increased. The concentrations of $\beta$-naphthylamine increased 59\% from 1968 to 1985 (8). Between 1978 and 1995, measured concentrations of tobacco-specific nitrosamines in filtered cigarettes increased $17 \%$ for $\mathrm{N}^{\prime}$-nitrosonornicotine and $44 \%$ for 4-(methylnitrosamino)-1-(3-pyridyl)-1-butanone (8). Some cigarette additives may be direct carcinogens or procarcinogens that are activated following combustion $(9,10)$. Others may increase tobacco carcinogenicity indirectly by affecting metabolic activation; for example, menthol may increase membrane permeability, thereby increasing the likelihood of carcinogens interacting with DNA (11).

The implementation of a consistent and methodologically rigorous case-control study protocol during an 11-year period in the same geographic region provides a unique opportunity to investigate

Affiliations of authors: Hollings Cancer Center and Division of Biostatistics and Epidemiology, Department of Medicine, Medical University of South Carolina, Charleston, SC (AJA); Cancer Prevention and Control Program and Department of Epidemiology and Biostatistics, Arnold School of Public Health, University of South Carolina, Columbia, SC (JRH).

Correspondence to: Anthony J. Alberg, PhD, MPH, Hollings Cancer Center, Medical University of South Carolina, 86 Jonathan Lucas St, PO Box 250955, Charleston, SC 29425 (e-mail: alberg@musc.edu).

See "Funding" following "References."

DOI: $10.1093 /$ jnci/djp385

(C) The Author 2009. Published by Oxford University Press. All rights reserved. For Permissions, please e-mail: journals.permissions@oxfordjournals.org. 
whether risk estimates changed over this period. Even with these strengths, if the observed increase in the association of smoking with bladder cancer over time is genuine, it is remarkable that it could be detected in such a narrow time interval. To illustrate if we assume that the median age of the bladder cancer patients was 65 years (12) and that the average age of smoking initiation was 15 years, the midpoint calendar year of smoking initiation for each of the three successive calendar year groups studied would be 1946, 1950 , and 1953. If a substantial portion of each study group began smoking in these years and remained smokers thereafter, the study groups that are compared would have substantial overlap in the calendar years smoked, and hence comparable exposure to similar types of cigarettes across time. If changes in cigarette composition were the primary determinant of the stronger smoking and bladder cancer association observed in more recent years, an extremely potent increase in bladder carcinogenicity would be needed to result in detectable changes at the population level.

So far, the changing carcinogenic properties of cigarettes have been studied most extensively for lung cancer, and it is known that this risk has increased over time (13). Furthermore, the relative risks of mortality from "other smoking-related cancers" increased for both men $(\mathrm{RR}=2.7$ to 3.5$)$ and women $(\mathrm{RR}=1.8$ to 2.6) when a cohort established in 1959, with follow-up through 1965, and another cohort established in 1982, with follow-up through 1988, were compared (14). For evidence specific to bladder cancer, we looked for a temporal trend in the associations from published cohort studies carried out in the United States that reported the RR for current smokers relative to nonsmokers in relation to bladder cancer incidence. No increase in the association was observed in successive and overlapping cohorts in Washington County, Maryland $(\mathrm{RR}=2.7$ for bladder cancer incidence in current smokers relative to nonsmokers in the first cohort, followed from 1963 to 1988 ; RR $=2.6$ in the second cohort, followed from 1975 to 1994) (15). A similar relative risk $(\mathrm{RR}=2.9)$ was reported in a Hawaiian cohort followed from 1966 to 1988 (16). In a few recent cohort studies, reported RRs of bladder cancer incidence among current smokers relative to nonsmokers were notably higher: 5.7 in Seventh Day Adventists followed from 1976 to 1982 (17) and 5.5 in the Iowa Women's Health Study cohort followed from 1986 to 1998 (18). This evidence is equivocal but certainly does not rule out that the association has grown stronger over time.

The findings of Baris et al. (7) are provocative and are accompanied by a tenable hypothesis. Recalling the steady accumulation of evidence and the cautious inferences that eventually led to the determination that smoking causes bladder cancer, these intriguing findings offer a testable hypothesis that warrants thorough investigation. An important element of this research will be to more precisely pinpoint the specific role of cigarette additives. This study highlights the need for continued vigilance in monitoring the impact of changing cigarette content and design on disease risk, and demonstrates that the public health implications of the changing cigarette content and design are potentially severe.

\section{References}

1. Lilienfeld AM, Levin M, Moore GE. The association of smoking with cancer of the urinary bladder in humans. Arch Intern Med. 1956;98(2): 129-135.

2. U.S. Department of Health Education and Welfare. Smoking and Health: Report of the Advisory Committee to the Surgeon General of the Public Health Service. Washington, DC: Public Health Service; 1964. Publication No. 1103.

3. U.S. Department of Health Education and Welfare. The Health Consequences of Smoking: A Report of the Surgeon General. Washington, DC: U.S. Department of Health Education and Welfare, Centers for Disease Control, Office on Smoking and Health 1979.

4. U.S. Department of Health and Human Services. The Health Consequences of Smoking: Cancer. A Report of the Surgeon General. Atlanta, GA: U.S. Department of Health and Human Services; 1982. Centers for Disease Control, Office on Smoking and Health.

5. U.S. Department of Health and Human Services. The Health Benefits of Smoking Cessation: A Report of the Surgeon General. Atlanta, GA: U.S. Department of Health and Human Services, Centers for Disease Control, Office on Smoking and Health 1990.

6. U.S. Department of Health and Human Services. The Health Consequences of Smoking: A Report of the Surgeon General.Atlanta, GA: U.S. Department of Health and Human Services; 2004. Centers for Disease Control and Prevention, Office on Smoking and Health.

7. Baris D, Karagas MR, Verrill C, et al. A case-control study of smoking and bladder cancer risk: emergent patterns over time. 7 Natl Cancer Inst. 2009;101(22):1553-1561.

8. National Cancer Institute. Risks Associated With Smoking Cigarettes With Low Machine-Measured Yields of Tar and Nicotine. Smoking and Tobacco Control Monograph No. 13. Bethesda, MD: U.S. Department of Health and Human Services, National Institutes of Health, National Cancer Institute, NIH Publication No. 02-5074.

9. Wogan GN, Hecht SS, Felton JS, Conney AH, Loeb LA. Environmental and chemical carcinogenesis. Semin Cancer Biol. 2004;14(6):473-486.

10. Turesky RJ. The role of genetic polymorphisms in metabolism of carcinogenic heterocyclic aromatic amines. Curr Drug Metab. 2004;5(2):169-180.

11. Azzi C, Zhang J, Purdon CH, et al. Permeation and reservoir formation of 4-(methylnitrosamino)-1-(3-pyridyl)-1-butanone (NNK) and benzo[a] pyrene (BAP) across porcine esophageal tissue in the presence of ethanol and menthol. Carcinogenesis. 2006;27(1):137-145.

12. Fortuny J, Kogevinas M, Zens MS, et al. Analgesic and anti-inflammatory drug use and risk of bladder cancer: a population based case control study. BMC Urol. 2007;7:13

13. Thun MJ, Lally CA, Flannery JT, Calle EE, Flanders WD, Heath CW. Cigarette smoking and changes in the histopathology of lung cancer. 7 Natl Cancer Inst. 1997;89(21):1580-1586.

14. Thun MJ, Day-Lally CA, Calle EE, Flanders WD, Heath CW. Excess mortality in cigarette smokers: changes in a 20 -year interval. Am $\mathcal{F}$ Public Health. 1995;85(9):1223-1230.

15. Alberg AJ, Kouzis A, Genkinger JM, Gallicchio L, Burke AE, Hoffman SC, Diener-West M, Helzlsouer KJ, Comstock GW. A prospective cohort study of bladder cancer risk in relation to active cigarette smoking and household exposure to secondhand smoke. Am 7 Epidemiol. 2007;165(6):660-666.

16. Chyou P-H, Nomura AMY, Stemmermann GN. A prospective study of diet, smoking, and lower urinary tract cancer. Ann Epidemiol. 1993;3(3):211-216.

17. Mills PK, Beeson WL, Phillips RL, Fraser GE. Bladder cancer in a low risk population: results from the Adventist Health Study. Am 7 Epidemiol. 1991;133(3):230-239.

18. Tripathi A, Folsom AR, Anderson KE. Risk factors for urinary bladder carcinoma in postmenopausal women. The Iowa Women's Health Study. Cancer. 2002;95(11):2316-2223.

\section{Funding}

National Cancer Institute (R01 CA105069 to A.J.A. and 1 UO1 CA114601 to J.R.H.). 